\title{
Loneliness and Mental Health : Critical Clinical Issues
}

\author{
Isha Dhingra ${ }^{1}$, Karishma Rupani ${ }^{2}$, Priyanka Thakral Mahajan ${ }^{3}$, Devanshi Desai ${ }^{4}$ \\ Avinash De Sousa ${ }^{4}$ \\ ${ }^{1,2}$ Specialty Medical Officer, \\ ${ }^{3}$ Senior Resident Doctor, \\ ${ }^{4}$ Research Assistant, \\ ${ }^{5}$ Research Associate, \\ 1,2,3,5 Department of Psychiatry, Lokmanya Tilak Municipal Medical College, Mumbai. \\ ${ }^{4}$ Desousa Foundation, Mumbai \\ E-mail - avinashdes888@gmail.com
}

\begin{abstract}
Loneliness signifies the adverse feeling resulting from social disconnectedness and the barrier between achieving one's desired social relations. The present review article primarily examines the interplay between loneliness and mental health. Though the available literature is large the following paper attempts to provide an overview of the various areas where loneliness and mental health are intertwined. The paper examines the basic concept of the construct of loneliness and differentiates it from other similar constructs. Loneliness has pertinent effects on physical health that in turn affect mental health. This is reviewed in a section followed by the effects of loneliness on mental health in general. Genetic factors as well as the neurobiological underpinnings of loneliness are examined. The effects of loneliness across the life span are also discussed with loneliness and its effects across age groups being examined. The factors determining the evolution of loneliness in humans is also examined. Though the paper follows a narrative rather than a systematic review paradigm, it gives the reader an overview of the various facets of loneliness and mental health. The paper also sums up the effect of loneliness on morbidity and mortality while exhorting the need for healthy social relationships in living. Various interventions that may be carried out for the prevention of loneliness are also discussed.
\end{abstract}

Keywords: Loneliness, mental health, social isolation, neurobiology, elderly, children.

\section{INTRODUCTION}

Social networks are important in our lives as each one of us often turns to our family, friends, co-workers and others for support when needed. It is essential to maintain social relationships for individual survival and well-being [1]. However, many individuals are unable to form and maintain these relationships and are plagued with social isolation and loneliness. It is important to understand that the terms 'social isolation' and 'loneliness' have different meanings [2]. Social isolation refers to a lack of social contact and support while 'loneliness' can be termed as adverse feelings due to a deficient social network and an inadequacy for social involvement. It refers to the individual perception associated with the divergence between their anticipated and achieved social relations [3]. Loneliness is the discomfort of social disconnection and the longing for social acceptance and connection. Loneliness has been described as "the subjective, unwelcome feeling of lack or loss of companionship" [4]. It has been divided into two distinct types: emotional loneliness and social loneliness. Emotional loneliness is personal, relating to satisfaction with existing opportunities to socialise while social loneliness is where people feel they do not have a wide social network, with support from friends or allies in times of distress [5]. Loneliness is often 
confused with social engagement, with the belief that getting people more involved in their communities or building up social networks will alleviate the problem. However, people who are fully engaged with their communities and have a wide social network can also feel lonely, while people who live on their own in isolation from society may never feel lonely [6]. The quality of social relationships plays an important role in whether or not people suffer from loneliness, as does their own life experience. Loneliness has far reaching ramifications as far as physical and mental health is concerned [7]. The current paper reviews the various areas where loneliness and mental health are linked providing an overview of the field.

\section{METHOD OF CONDUCTING THIS REVIEW}

For identifying articles that focused on loneliness and mental health, the terms 'loneliness', 'loneliness and mental health', 'neurobiology of loneliness', 'genetics of loneliness', 'loneliness and old age', 'loneliness in children and adolescents' or 'social isolation' were used. For identifying articles that focused on specific terms, words like 'anxiety', 'anxiety disorder', 'depression', 'health related quality of life', 'physical health', 'medical illness', 'evolution', 'psychosocial interventions' and other like terms were used. These two search strategy results were combined with an 'and' statement in the following data bases with the time frame being specified from 2000 through 2016. The databases used were Medline, Pubmed, Scopus and the Cochrane Database on Systematic Reviews. In total, 278 articles were identified which included reviews, mini reviews, research papers and randomized studies in populations with loneliness or at a risk of social isolation. Most of the papers were clinical research and many review papers both narrative and systematic were identified.

We included studies with sample sizes of more than 50 participants (where needed in the discussion). Most of the reviews were read by all the authors and key papers were identified for inclusion in this paper. The papers reviewed in this article include original research articles, reviews and intervention studies. This is supplemented with the personal clinical experience of all the authors in this field who work regularly with this group of patients who experience loneliness. All the authors are psychiatrists working in a tertiary hospital and medical college in Mumbai where loneliness is commonly reported in the psychopathological evaluation of patients.

\section{LONELINESS AND PHYSICAL HEALTH - IMPLICATIONS FOR MENTAL HEALTH}

The physiological systems of individuals that are lonely take up more impact of the stressors confronted in daily lives and are unable to moderate stress responses when compared to individuals who have supportive social ties [8]. Studies have shown that lonely individuals undergo high levels of stress and reported perceiving their daily chores to be more stressful and threatening than compared to non-lonely individuals [9]. It can be seen that blood pressure differed between lonely and non-lonely individuals where lonely individuals were depicted by high peripheral resistance (TPR) and lower cardiac output [10]. Five-year cross-lagged analyses in middle aged and older adults revealed increases in systolic blood pressure (SBP) due to loneliness 2,3 and 4 years later with more increases in SBP being linked with greater initial levels of loneliness [11]. Peripheral resistance plays an important role in order to determine blood pressure over the years. Chronic cardio-vascular diseases stem from elevated blood pressure and these facts suggest that the deficiencies in perceived social bonds is related to differences in physiological functioning and could cause serious health consequences [12]. Loneliness has also been linked to accelerated physiological aging and a faster deterioration of the body's physiological systems as in response to chronic stress [13]. Smoking, another factor related to cardiovascular morbidity has been linked to loneliness and many studies report that lonely individuals tend to smoke more than individuals with good social support [14]. Other cardiovascular physiological changes like increased arterial stiffness, decreased release of nitric oxide by endothelial cells, enhanced responsiveness of the vascular endothelium to endothelial constrictive factors and oxidative stress has been documented in response to loneliness [15]. Loneliness may also lead to poor lifestyle causing dietary disturbances, poor sleep and obesity that in turn may trigger physical disease [16]. It is well known that various lifestyle diseases and cardiovascular illnesses have in turn implications for mental health as well [17]. 


\section{EFFECTS OF LONELINESS ON COGNITIVE FUNCTION}

Loneliness is known to cause a multitude of cognitive effects. First, loneliness increases explicit attention to social stimuli and increases implicit attention to social threats whoich is further confirmed via functional MRI studies [18]. Lonely people are viewed more negatively in terms of their psychosocial functioning and in terms of their interpersonal attraction or acceptance than are nonlonely people [19]. Using a modified emotional Stroop task, lonely participants, relative to non-lonely participants, showed greater Stroop interference specifically for negative social relative to negative nonsocial words [20]. There have been differences in the pattern of regional brain activation produced by lonely and non-lonely individuals when thinking about people. Activation of the visual cortex to the presentation of unpleasant social, in contrast to nonsocial, pictures was directly related to the loneliness of the participant, indicative of greater visual attention to the negative social stimuli [21]. These results are consistent with the behavioral data indicating that loneliness is related to an attentional bias for negative social stimuli [22].

Loneliness has yet another cognitive consequence. It diminishes self-regulation. Poorer self-regulation when feeling isolated is not limited to attention control. In cross-sectional and longitudinal research, lonely individuals have been found to have lower odds of engaging in regular exercise than non-lonely individuals, and the poorer emotional regulation of individuals when they felt lonely mediated the effect [23]. A perceived future of social isolation causes impairment in higher order cognitive and self-regulatory processes that are characteristic of executive functioning. A brain scan conducted while participants performed moderately difficult math problems revealed that the brains of the socially isolated participants were less active in the areas involved in the "executive control" of attention [24].

Loneliness is also a major risk factor for cognitive decline and dementia [25]. In the mental ability situations studied over years, after controlling for various important variables such as age, years of education etc, findings suggested that loneliness was linked with alterations in IQ [26]. In addition, a longitudinal study where cognition was measured over 1, 5 and 10 years suggested that loneliness predicted cognitive decline [27]. When dementia free individuals were studied for cognitive skills such as different types of memories, the findings suggested a negative correlation between the level of loneliness and cognitive performance, positive correlation between loneliness and cognitive decline and some individuals even developed dementia [28]. These studies illustrate that feelings of loneliness can impact cognition in different ways either as consequence or as a predictor [29]. The exact relationship between cognition and loneliness is not well understood. One possibility is such that deficiencies in cognitive functioning may lead to social disconnectedness; poorer social interactions and promote withdrawal that may result in an individual feeling lonely [30]. It is essential to address and carry out additional studies to understand the causality and the mechanism behind the association between cognitive defects and loneliness.

\section{LONELINESS AND MENTAL HEALTH}

Social isolation and loneliness has been associated with persistent mental illness and has a strong relationship and influence on the psychological well being of individuals. It has roots in determining symptoms of depression [31] and is also associated with psychosis and schizophrenia [32]. Interpersonal aspects such as social support, social acceptance, and social divergence have been linked to depression [33]. Loneliness when experienced by humans may manifest as depressive symptoms. There are discrepancies in understanding the causal nature of the relation between loneliness and depressive symptoms. It has been shown that the two often co-occur and that when measures of both loneliness and depression were manipulated amongst patients at points in intervals, the two were correlated [34]. Higher levels of loneliness are related to increase in depressive symptoms. When lonely and non-lonely individuals are compared, the lonely individual exhibit increased levels of depressed mood [35]. In a longitudinal study, the casual nature of the two was examined addressing psychosocial variables such as 
perceived stress, social support, social network size etc where it was seen that loneliness was yet again associated with more depressive symptoms over a period of 3 years. It was discovered that there are reciprocal influences overtime between the two [36]. The reasoning behind social isolation and depression could be such that loneliness may threaten feelings of personal worth due to the perceived incapability's of an individual and result in not being able to manage the pain and feelings of disability that comes along with it which may lead to depressive symptoms [37].

Alzheimer's dementia is one of the commonest causes of dementia worldwide and has been linked to loneliness. A follow-up study revealed that when lonely individuals were compared to non-lonely individuals, they had more than double the chance of developing Alzheimer's disease even when all the variables of social isolation were controlled. Initially, loneliness showed poor cognition and at the follow-up there was cognitive decline [38].

In addition, the struggle to form interpersonal relationships and diminished social support is commonly found in individuals experiencing psychosis or schizophrenia [39]. These features of psychosis tend to abide by the feelings experienced by lonely individuals. It is seen that symptoms of psychosis is related to less fulfillment of social support and loneliness and it is also studied that this association between loneliness and psychosis could be reduced when anxiety is controlled as it could be one of the leading ways through which loneliness affects psychosis [40]. Lonely individuals have been reported to have an increased tendency to develop a mental illness when all factors otherwise are controlled [41].

Loneliness has also been associated with sleep fragmentation. Loneliness heightens the attentiveness to social threat, which in turn may affect sleep. While sleep efficiency was studied in lonely and non-lonely individuals it is seen that loneliness was associated to greater microawakenings and reduced restful sleep [42]. A study wherein adults were tested for sleep efficiency, by the use of a Nightcap in order to record their sleep showed that lonely adults exhibited poorer sleep efficiency and the wake time onset after sleep was greater when compared to non-lonely adults [43]. Furthermore, it has been seen that self report measures of sleep quality like the Pittsburgh Sleep Quality Inventory revealed poor sleep quality, greater perceived sleep duration, and daytime dysfunction in lonely individuals than non-lonely individuals [44]. Compromised sleep and poor sleep quality may be linked to various health outcomes such as increased cardiovascular morbidity, impaired mental health as well as impaired cognitive skills and the individual may be less efficient due to the daytime dysfunction [45].

\section{GENETICS AND LONELINESS}

Loneliness has been reported to be heritable and genetic in nature. In a study where 22 monozygotic and 40 dizygotic twins were compared to assess loneliness by the means of 16-item scale, the heritability estimate was $55 \%$ and $48 \%$ respectively, which showed that there is a genetic contribution to loneliness [46]. Candidate gene research concentrates on the genes for loneliness in association with neurotransmitters. The neurotransmitter responsible for social behavior is oxytocin [47]. Individuals who have GG phenotype at SNPs in the oxytocin receptor gene exhibit more sociability and trust in others. In studying the gene effects, it is seen that the individuals with the GG phenotype in the OXTR gene had significantly less chances of being lonely [48]. Loneliness is known to be significantly heritable, with genes playing a role in susceptibility to environmental stressors, as has been seen with other psychiatric illnesses as well [49]. Other genes that have been implicated are MTFHR, CHRNa4, BDNF, and the serotonin transporter gene. Phenotypic variants of the BDNF gene show a gender difference as boys with the Val/Val type of BDNF rs62625 and girls with the Met/Met type are found to be lonelier. The short allele of the serotonin transporter gene is associated with the inefficient dampening of negative emotions [49].

\section{NEUROBIOLOGY AND LONELINESS}

The neurobiology of loneliness has been explored largely by means of animal studies. The areas of the human brain posited to be associated with loneliness are the prefrontal cortex, 
temporoparietal junction, visual cortex, hippocampus, amygdala and striatum [50]. It has been found that the social isolation of animals is associated with altered levels of various neurotrophic factors and neurohormones such as brain-derived neurotrophic factor (BDNF), nerve growth factor (NGF), corticosterone, GABA and allopregnanalone [51]. It has been hypothesized that fluoxetine may mitigate the behavioral effects of loneliness via allopregnanolone rather than serotonin, as allopregnenolone facilitates GABA and upregulates BDNF [52]. Social isolation is also associated with reduced proliferation, differentiation and ongoing myelination of the nerve cells, especially in the prefrontal cortex [53]. Environmental stimulation has also been linked to brain volume and information processing capacity, as per the social brain hypothesis. Conversely, increased sociability may lead to faster and fuller recovery following neural injury such as from cerebral ischemia, and may protect against cognitive decline [54]. As per the evolutionary theory, loneliness is an important aversive stimulus that promotes social interaction [55]. However, constant stress may take a toll on the body's capacity for homeostasis [56]. The primary mediators of the aversive neuroendocrinological impact of the stress and social isolation are hypothalamic-pituitary adrenocortical (HPA) axis and the sympathetic autonomic nervous system [57]. Social support confers greater resilience and better physiological control of the aforementioned two systems. From animal studies, sociability appears to be mediated primarily by oxytocin and vasopressin [58]. Dysregulation of the HPA axis also contributes to hypertension, atherosclerosis and coronary artery disease via intravascular inflammation [59]. Loneliness is also associated with elevated urinary and salivary cortisol and this appears to be specifically related to hypervigilance, negative social evaluation and a feeling of lack of control [60].

Loneliness also has an array of consequences on the immune system [61]. Natural killer cell activity, one of the defenses against cancer, has been found to be compromised in a study conducted in lonely medical students [62]. The response of inflammatory cytokines such as interleukin-1 (IL-1) and tumor necrosis factor (TNF) to lymphocytes is also compromised in lonely individuals [63]. Loneliness also appears to adversely impact wound healing time [64]. Studies have also shown that chronic over activation of the HPA axis, particularly in relation to loneliness, is associated with glucocorticoid resistance and a complimentary gene in pro-inflammatory gene expression, which contribute to ill-health and morbidity [65].

\section{LONELINESS IN CHILDREN AND ADOLESCENTS}

Chronic feelings of loneliness develop during the attachment process in early childhood and tend to significantly impact personality and behavior in later life. Children as young as five to six years of age are able to understand the basic concept of loneliness and can be assessed for the same [66]. Childhood loneliness is also commonly associated with severe psychiatric syndromes like depression, borderline personality disorder and schizophrenia in later life [67]. Peer relations play an important role in the development of loneliness in children [68]. Researchers have described two kinds of lonely children rejected (or disliked) and neglected (neither liked nor disliked), with a greater degree of loneliness seen in the rejected subtype, especially those who were rejected for being submissive rather than overbearing. They also found that maintaining even a single friendship helped mitigate the degree of loneliness in these children [69]. Biologically, volume changes are seen in the ventral striatum, hippocampus, amygdala, anterior cingulate cortex and orbitofrontal cortex secondary to childhood adversity [70]. It has been found that right-hemisphere dominance leads to more trait negative-affectivity; rejected children with this trait therefore have a compounded likelihood of experiencing loneliness [71]. Trait shyness and right hemisphere dominance predispose to a greater likelihood of the child suffering internalizing problems. Further, negative affectivity leads to a negative impression on others, pushing away potential companions and perpetuating the cycle [72].

In keeping with the above mention of the interaction between environmental stressors and a genetic predisposition to loneliness, it has been found that social support can have a modifying effect on the risk posed by maltreatment in genetically predisposed children [73]. Training children in social skills has also been found to ameliorate loneliness and increase acceptance by peers in older studies, but recent interventional research in this regard is lacking [74]. Adolescence is especially a 
time of social and personal change, which can aggravate feelings of loneliness. Not surprisingly, loneliness is widespread among adolescents [75]. Loneliness is a product of the interactions between state and trait i.e. between the environment and the individual. Lonely adolescents share certain characteristics such as attributing failure to personal character rather than circumstances, attributing success more to circumstances, feeling a lack of control over their own successes and failures, having fewer friends and the decreased likelihood of having a romantic partner [76]. These findings are supported by another, older study, which additionally found that adolescent loneliness was positively related to social anxiety and negatively related to self-reported attractiveness, likability, happiness, and life satisfaction. The same study reports that adolescents most often attributed loneliness to boredom and commonly turned to television or music to cope with it [77]. Culture plays a role; although adolescent loneliness is pervasive across all races and cultures, the perception of the same has been shown to vary with differing cultural backgrounds [78].

\section{LONELINESS AND AGEING}

Ageing is a biological process that is influenced by numerous factors and characterised by multiple changes in human body, but is not under anyone's control [79]. In most developed countries, beginning of old age is marked by the age of retirement (60-65 years). While people at all ages are susceptible to loneliness, it is particularly acute and common in the elderly [80]. This is on account of multiple reasons, such as loss of financial independence post retirement, social isolation (bereavement due to loss of life partner and friends), and disability due to physical constraints [81]. The elderly typically face a dual problem of social isolation and loneliness. Studies have shown that around 10$43 \%$ of elderly experience social isolation and $5-16 \%$ report loneliness [82]. Continued increase in life expectancy, driven by continuous improvement in medical facilities and disposable income of individuals, has led to further increase in the incidence of loneliness [83].

Loneliness particularly impacts cognition in the elderly. It leads to dementia and Alzheimer's disease. Studies have shown that loneliness impacts all the 3 components of memory viz. semantic, working and episodic, along with the speed of processing [84]. Besides cognition, loneliness also affects the physical health of the elderly. Studies have shown that with increasing age, there is a rise in systolic blood pressure in lonely people. This increases the risk of cardiac disease and also affects the amount of urine epinephrine levels [85]. In addition to the above, there are multiple psychological effects of loneliness in the elderly. These include low self-esteem, anxiety, depression, restlessness, sleep disorders, alcohol abuse, suicidal behaviour, feeling helplessness and threat, behavioural withdrawal, sense of emptiness, shyness, negative emotions, impaired quality of life, disability, etc [86].

There are many alternatives to treat loneliness in the elderly. One is to increase their social interactions by participating in group interventions with them. Additionally, peer support activities like art and drama, same age friendship networks, religious and educational activities, and voluntary work like gardening, are also helpful. Teaching elderly people new technology such as internet and skype can also be helpful, since these have the potential to reduce their social isolation [87]. Further, one can work towards ensuring that the elderly have adequate income to support their lifestyle. Alternatives here include providing them options to invest in pension schemes, allowing them to work even after retirement, organizing classes aimed at the elderly to improve their educational status, or providing them access to social service. Educating them to make life adjustments such as, lowering their expectations and acceptances is also typically helpful [88].

\section{INTERVENTIONS TO REDUCE LONELINESS}

If loneliness persists for a long time, it can cause both physical and mental health problems ${ }^{1 .}$ Thus, management of loneliness needs to be done at the earliest. Various interventions that can help mitigate loneliness are as follows -

- Improving Social Skills - This intervention was earlier practiced to reduce shyness and anxiety among patients but was observed to be effective in treating loneliness. The focus of this intervention is to improve conversational skills urging the subject to speak on telephone, give and 
receive complements, handle periods of silence, and introduce non-verbal communication methods and approaches to physical fantasy. Support groups are very helpful in imparting social skills training [89].

- Enhancing Social Support : Studies have shown that providing social support helps people whose social network has been disrupted by various factors, such as relocation especially in the elderly, death of a loved one/bereaved or in children with divorced parents. Mutual help groups help increase social support especially in patients with psychiatric illness [90].

- Increasing opportunities of social contact/interaction : This intervention mainly addresses people with social isolation. Studies have been done on elderly individuals living in a hotel where a blood pressure programme was conducted in the hotel lobby. This led to increased interaction over time in the lobby despite the subjects' physical disabilities [91].

- Addressing social cognition : This is the most important and the most successful intervention for reducing loneliness. Here, the focus is primarily on Cognitive Behaviour Therapy (CBT). Subjects are taught to identify their negative thoughts, and regard them as hypotheses to be tested. Self-help groups are helpful in replacing the negative and fearful thinking with positive and self-supportive thinking [92].

Various interventions have been documented across studies aimed at reducing loneliness. These interventions are classified under four broad categories : [93]

a. Group Activities such as teleconferencing, support groups, and friendship enrichment training, which were also designed to improve social interaction and social skills.

b. One-to-one Activities like telephone based and gatekeeper programs to enhance social interaction and social support.

c. Service provision focussed on social interactions

d. Whole community approach

\section{CONCLUSIONS}

Human being is a social animal. $80 \%$ of his waking hours is spent with other human being i.e. friends, family members and colleagues at work. Human social behavior has evolved over the ages and also involves positive neural and biochemical changes with it. Failure to socialize and the development of loneliness may have detrimental neurobiological and psychological consequences. A variety of medical and psychological disorders have been linked with loneliness as a risk factor. Loneliness is seen across the life span and across both sexes. Loneliness whether in children or in the elderly has negative consequences both short term and long term. Interventions aimed at reducing loneliness while thereby alleviating the burden of physical and mental illness need to designed as with increase in time there is bound to be a rise in the number of individuals that manifest with loneliness as a risk factor.

\section{REFERENCES}

1. McPherson M, Smith-Lovin L, Brashears ME. Social isolation in America: Changes in core discussion networks over two decades. Am Sociol Rev 2006;71(3):353-75.

2. ElSadr CB, Noureddine S, Kelley J. Concept analysis of loneliness with implications for nursing diagnosis. Int J Nurs Term Classif 2009;20(1):25-33.

3. Sarason IG (Ed). Social support: Theory, research and applications. Springer Science \& Business Media : New York; 2013.

4. Ernst JM, Cacioppo JT. Lonely hearts: Psychological perspectives on loneliness. Appl Prev Psychol 2000;8(1):1-22.

5. Cattan M, Newell C, Bond J, White M. Alleviating social isolation and loneliness among older people. Int J Ment Health Prom 2003;5(3):20-30.

6. Chipuer HM. Dyadic attachments and community connectedness: Links with youths' loneliness experiences. J Commun Psychol 2001;29(4):429-46.

7. Holt-Lunstad J, Smith TB, Layton JB. Social relationships and mortality risk: a meta-analytic review. PLoS Med 2010;7(7):e1000316. 
8. Cacioppo JT, Hawkley LC, Berntson GG. The anatomy of loneliness. Curr Dir Psychol Sci 2003;12(3):71-4.

9. Cacioppo JT, Cacioppo S, Cole SW, Capitanio JP, Goossens L, Boomsma DI. Loneliness across phylogeny and a call for comparative studies and animal models. Persp Psychol Sci 2015;10(2):202-12.

10. Hawkley LC, Burleson MH, Berntson GG, Cacioppo JT. Loneliness in everyday life: Cardiovascular activity, psychosocial context, and health behaviors. J Pers Soc Psychol 2003;85(1):105-20.

11. Hawkley LC, Thisted RA, Masi CM, Cacioppo JT. Loneliness Predicts Increased Blood Pressure: FiveYear Cross-Lagged Analyses in Middle-Aged and Older Adults. Psychol Aging 2010;25(1):132-41.

12. Hawkley LC, Cacioppo JT. Loneliness and pathways to disease. Brain Behav Immun 2003;17(1):98-105.

13. Shankar A, McMunn A, Banks J, Steptoe A. Loneliness, social isolation, and behavioral and biological health indicators in older adults. Health Psychol 2011;30(4):377-85.

14. DeWall CN, Pond Jr RS. Loneliness and smoking: The costs of the desire to reconnect. Self Identity 2011;10(3):375-85.

15. Kiecolt-Glaser JK, Gouin JP, Hantsoo L. Close relationships, inflammation, and health. Neurosci Biobehav Rev 2010;35(1):33-8.

16. Kärner A, Tingström $P$, Abrandt-Dahlgren M, Bergdahl B. Incentives for lifestyle changes in patients with coronary heart disease. J Adv Nurs 2005;51(3):261-75.

17. Asti T, Kara M, Ipek G, Erci B. The experiences of loneliness, depression, and social support of Turkish patients with continuous ambulatory peritoneal dialysis and their caregivers. J Clin Nurs 2006;15(4):490-7.

18. Sorkin D, Rook KS, Lu JL. Loneliness, lack of emotional support, lack of companionship, and the likelihood of having a heart condition in an elderly sample. Ann Behav Med 2002;24(4):290-8.

19. Cacioppo JT, Hawkley LC, Norman GJ, Berntson GG. Social isolation. Ann NY Acad Sci 2011;1231:1722.

20. Brewer MB. Taking the Social Origins of Human Nature Seriously: Toward a More Imperialist Social Psychology. Pers Soc Psychol Rev 2004;8(2):107-13.

21. DeWall CN, Maner JK, Rouby DA. Social exclusion and early-stage interpersonal perception: selective attention to signs of acceptance. J Pers Soc Psychol 2009;96(4):729-36.

22. Taylor CT, Bomyea J, Amir N. Attentional bias away from positive social information mediates the link between social anxiety and anxiety vulnerability to a social stressor. J Anxiety Disord 2010;24(4):403-8.

23. Fox NA, Henderson HA, Marshall PJ, Nichols KE, Ghera MM. Behavioral inhibition: linking biology and behavior within a developmental framework. Annu Rev Psychol 2005;56:235-62.

24. Cacioppo JT, Cacioppo S. Older adults reporting social isolation or loneliness show poorer cognitive function 4 years later. Evid Based Nurs 2013;17:59-60.

25. Moyle W, Kellett U, Ballantyne A, Gracia N. Dementia and loneliness: an Australian perspective. J Clin Nurs 2011;20(9-10):1445-53.

26. Bauminger N, Shulman C, Agam G. Peer interaction and loneliness in high-functioning children with autism. J Autism Dev Disord 2003;33(5):489-507.

27. Wilson RS, Krueger KR, Arnold SE, Schneider JA, Kelly JF, Barnes LL, Tang Y, Bennett DA. Loneliness and risk of Alzheimer disease. Arch Gen Psychiatry 2007;64(2):234-40.

28. Vitaliano PP, Murphy M, Young HM, Echeverria D, Borson S. Does caring for a spouse with dementia promote cognitive decline? A hypothesis and proposed mechanisms. J Am Geriatr Soc 2011;59(5):900-8.

29. Cacioppo JT, Hawkley LC. Perceived social isolation and cognition. Trends Cogn Sci 2009;13(10):447-54.

30. Conroy RM, Golden J, Jeffares I, O'Neill D, McGee H. Boredom-proneness, loneliness, social engagement and depression and their association with cognitive function in older people: a population study. Psychol Health Med 2010;15(4):463-73.

31. Kim O, Byeon YS, Kim JH, Endo E, Akahoshi M, Ogasawara H. Loneliness, depression and health status of the institutionalized elderly in Korea and Japan. Asian Nurs Res 2009;3(2):63-70.

32. Roe D, Mashiach-Eizenberg M, Lysaker PH. The relation between objective and subjective domains of recovery among persons with schizophrenia-related disorders. Schizophr Res 2011;131(1):133-8.

33. Stice E, Ragan J, Randall P. Prospective relations between social support and depression: Differential direction of effects for parent and peer support?. J Abnorm Psychol 2004;113(1):155-9.

34. Lin N, Dean A, Ensel WM (Eds). Social support, life events, and depression. Academic Press; 2013.

35. Adams KB, Sanders S, Auth E. Loneliness and depression in independent living retirement communities: risk and resilience factors. Aging Ment Health 2004;8(6):475-85.

36. Swami V, Chamorro-Premuzic T, Sinniah D, Maniam T, Kannan K, Stanistreet D, Furnham A. General health mediates the relationship between loneliness, life satisfaction and depression. Social Psych Psychiatr Epidemiol 2007;42(2):161-6.

37. Kim O. Sex differences in social support, loneliness, and depression among Korean college students. Psychol Rep 2001;88(2):521-6. 
38. Holwerda TJ, Deeg DJ, Beekman AT, van Tilburg TG, Stek ML, Jonker C, Schoevers RA. Feelings of loneliness, but not social isolation, predict dementia onset: results from the Amsterdam Study of the Elderly (AMSTEL). J Neurol Neurosurg Psychiatry 2014;85(2):135-42.

39. Nilsson B, Lindström UÅ, Nåden D. Is loneliness a psychological dysfunction? A literary study of the phenomenon of loneliness. Scand J Caring Sci 2006;20(1):93-101.

40. Kudo J, Mori H, Gomibuchi T. Loneliness as expressed by schizophrenic patients in the early remission phase. Nagoya J Med Sci 2002;65(3-4):115-26.

41. Nilsson B, Nåden D, Lindström UÅ. The tune of want in the loneliness melody-loneliness experienced by people with serious mental suffering. Scand J Caring Sci 2008;22(2):161-9.

42. Kurina LM, Knutson KL, Hawkley LC, Cacioppo JT, Lauderdale DS, Ober C. Loneliness is associated with sleep fragmentation in a communal society. Sleep 2011;34(11):1519-26.

43. Cacioppo JT, Hawkley LC, Berntson GG, Ernst JM, Gibbs AC, Stickgold R, Hobson JA. Do lonely days invade the nights? Potential social modulation of sleep efficiency. Psychol Sci 2002;13(4):384-7.

44. Cacioppo JT, Ernst JM, Burleson MH, McClintock MK, Malarkey WB, Hawkley LC, Kowalewski RB, Paulsen A, Hobson JA, Hugdahl K, Spiegel D. Lonely traits and concomitant physiological processes: the MacArthur social neuroscience studies. Int J Psychophysiol 2000;35(2):143-54.

45. Jaremka LM, Fagundes CP, Peng J, Bennett JM, Glaser R, Malarkey WB, Kiecolt-Glaser JK. Loneliness promotes inflammation during acute stress. Psychol Sci 2013;24(7):1089-97.

46. McHugh JE, Lawlor BA. Perceived stress mediates the relationship between emotional loneliness and sleep quality over time in older adults. Br J Health Psychol 2013;18(3):546-55.

47. Insel TR, Young LJ. The neurobiology of attachment. Nat Rev Neurosci 2001;2(2):129-36.

48. Lucht MJ, Barnow S, Sonnenfeld C, Rosenberger A, Grabe HJ, Schroeder W, Völzke H, Freyberger HJ, Herrmann FH, Kroemer H, Rosskopf D. Associations between the oxytocin receptor gene (OXTR) and affect, loneliness and intelligence in normal subjects. Prog Neuropsychopharmacol Biol Psychiatry 2009;33(5):860-6.

49. Goossens L, Van Roekel E, Verhagen M, Cacioppo JT, Cacioppo S, Maes M, Boomsma DI. The Genetics of Loneliness Linking Evolutionary Theory to Genome-Wide Genetics, Epigenetics, and Social Science. Persp Psychol Sci 2015;10(2):213-26.

50. Burgdorf J, Panksepp J. The neurobiology of positive emotions. Neurosci Biobehav Rev 2006;30(2):173-87.

51. Cacioppo S, Capitanio JP, Cacioppo JT. Toward a neurology of loneliness. Psychol Bull 2014;140(6):1464504.

52. Nin MS, Martinez LA, Pibiri F, Nelson M, Pinna G. Neurosteroids reduce social isolation-induced behavioral deficits: a proposed link with neurosteroid-mediated upregulation of BDNF expression. Neurosteroids 2011;21:265.

53. Mitchell JP, Banaji MR, MacRae CN. The link between social cognition and self-referential thought in the medial prefrontal cortex. J Cogn Neurosci 2005;17(8):1306-15.

54. Young LJ. The neurobiology of social recognition, approach, and avoidance. Biol Psychiatry 2002;51(1):1826.

55. DiTommaso E, Brannen-McNulty C, Ross L, Burgess M. Attachment styles, social skills and loneliness in young adults. Personal Individ Diff 2003;35(2):303-12.

56. Monroe SM. Modern approaches to conceptualizing and measuring human life stress. Annu Rev Clin Psychol 2008;4:33-52.

57. McEwen BS. Physiology and neurobiology of stress and adaptation: central role of the brain. Physiol Rev 2007;87(3):873-904.

58. Strathearn L. Maternal neglect: oxytocin, dopamine and the neurobiology of attachment. J Neuroendocrinol 2011;23(11):1054-65.

59. Kudielka BM, Kirschbaum C. Sex differences in HPA axis responses to stress: a review. Biol Psychol 2005;69(1):113-32.

60. Doane LD, Adam EK. Loneliness and cortisol: Momentary, day-to-day, and trait associations. Psychoneuroendocrinology 2010;35(3):430-41.

61. Hawkley LC, Bosch JA, Engeland CG, Marucha PT, Cacioppo JT. Loneliness, dysphoria, stress and immunity: A role for cytokines. Cytokines: Stress and immunity 2007:67-85.

62. Steptoe A, Owen N, Kunz-Ebrecht SR, Brydon L. Loneliness and neuroendocrine, cardiovascular, and inflammatory stress responses in middle-aged men and women. Psychoneuroendocrinology 2004;29(5):593611.

63. Hackett RA, Hamer M, Endrighi R, Brydon L, Steptoe A. Loneliness and stress-related inflammatory and neuroendocrine responses in older men and women. Psychoneuroendocrinology 2012;37(11):1801-9. 
64. Detillion CE, Craft TK, Glasper ER, Prendergast BJ, DeVries AC. Social facilitation of wound healing. Psychoneuroendocrinology 2004;29(8):1004-11.

65. Cole SW. Social regulation of leukocyte homeostasis: The role of glucocorticoid sensitivity. Brain Behav Immun 2008;22(7):1049-55.

66. Asher SR, Paquette JA. Loneliness and peer relations in childhood. Curr Dir Psychol Sci 2003;12(3):75-8.

67. Storch EA, Masia-Warner C. The relationship of peer victimization to social anxiety and loneliness in adolescent females. J Adolesc 2004;27(3):351-62.

68. Margalit M. Lonely children and adolescents: Self-perceptions, social exclusion, and hope. Springer Science \& Business Media; 2010.

69. Nangle DW, Erdley CA, Newman JE, Mason CA, Carpenter EM. Popularity, friendship quantity, and friendship quality: Interactive influences on children's loneliness and depression. J Clin Child Adolesc Psychol 2003;32(4):546-55.

70. Holz NE, Laucht M, Meyer-Lindenberg A. Recent advances in understanding the neurobiology of childhood socioeconomic disadvantage. Curr Opin Psychiatry 2015;28(5):365-70.

71. Cacioppo JT, Patrick W. Loneliness: Human nature and the need for social connection. WW Norton \& Company; 2008.

72. Jackson T, Fritch A, Nagasaka T, Gunderson J. Towards explaining the association between shyness and loneliness: A path analysis with American college students. Social Behav Personality 2002;30(3):263-70.

73. Cheng H, Furnham A. Personality, peer relations, and self-confidence as predictors of happiness and loneliness. J Adolesc 2002;25(3):327-39.

74. Merrell KW, Gimpel G. Social skills of children and adolescents: Conceptualization, assessment, treatment. Psychology Press; 2014.

75. Storch EA, Brassard MR, Masia-Warner CL. The relationship of peer victimization to social anxiety and loneliness in adolescence. Child Study J 2003;33(1):1-9.

76. Cacioppo JT, Hawkley LC, Ernst JM, Burleson M, Berntson GG, Nouriani B, Spiegel D. Loneliness within a nomological net: An evolutionary perspective. J Res Personality 2006;40(6):1054-85.

77. Moore D, Schultz Jr NR. Loneliness at adolescence: Correlates, attributions, and coping. J Youth Adolesc 1983;12(2):95-100.

78. Rokach A. Loneliness and the life cycle. Psychol Rep 2000;86(2):629-42.

79. Rockwood K. What would make a definition of frailty successful?. Age Ageing 2005;34(5):432-4.

80. Koropeckyj-Cox T. Loneliness and depression in middle and old age: Are the childless more vulnerable?. J Gerontol Series B: Psychol Sci Soc Sci 1998;53(6):S303-12.

81. Luo Y, Hawkley LC, Waite LJ, Cacioppo JT. Loneliness, health, and mortality in old age: A national longitudinal study. Social Sci Med 2012;74(6):907-14.

82. Savikko N, Routasalo P, Tilvis RS, Strandberg TE, Pitkälä KH. Predictors and subjective causes of loneliness in an aged population. Arch Gerontol Geriatr 2005;41(3):223-33.

83. Victor CR, Scambler SJ, Bowling AN, Bond J. The prevalence of, and risk factors for, loneliness in later life: a survey of older people in Great Britain. Ageing Soc 2005;25(6):357-75.

84. Buchman AS, Boyle PA, Wilson RS, James BD, Leurgans SE, Arnold SE, Bennett DA. Loneliness and the rate of motor decline in old age: the rush memory and aging project, a community-based cohort study. BMC Geriatr 2010;10(1):1.

85. Luanaigh CÓ, Lawlor BA. Loneliness and the health of older people. Int J Geriatr Psychiatry 2008;23(12):1213-21.

86. Cacioppo JT, Hawkley LC, Thisted RA. Perceived social isolation makes me sad: 5-year cross-lagged analyses of loneliness and depressive symptomatology in the Chicago Health, Aging, and Social Relations Study. Psychol Aging 2010;25(2):453-63.

87. Cattan M, White M, Bond J, Learmouth A. Preventing social isolation and loneliness among older people: a systematic review of health promotion interventions. Ageing Society 2005;25(1):41-67.

88. Routasalo P, Pitkala KH. Loneliness among older people. Rev Clin Gerontol 2003;13(04):303-11.

89. Gierveld JD, Dykstra PA. Virtue is its own reward? Support-giving in the family and loneliness in middle and old age. Ageing Society 2008;28(2):271-87.

90. Tomaka J, Thompson S, Palacios R. The relation of social isolation, loneliness, and social support to disease outcomes among the elderly. J Aging Health 2006;18(3):359-84.

91. Uchino BN. Social support and health: a review of physiological processes potentially underlying links to disease outcomes. J Behav Med 2006;29(4):377-87.

92. Chiang KJ, Chu H, Chang HJ, Chung MH, Chen $\mathrm{CH}$, Chiou HY, Chou KR. The effects of reminiscence therapy on psychological well-being, depression, and loneliness among the institutionalized aged. Int J Geriatr Psychiatry 2010;25(4):380-8. 
93. Masi CM, Chen HY, Hawkley LC, Cacioppo JT. A meta-analysis of interventions to reduce loneliness. Personal Soc Psychol Rev 2011;15(3):219-66.

Acknowledgements - Nil

Source of Funding - Nil

Conflict of Interest - Nil

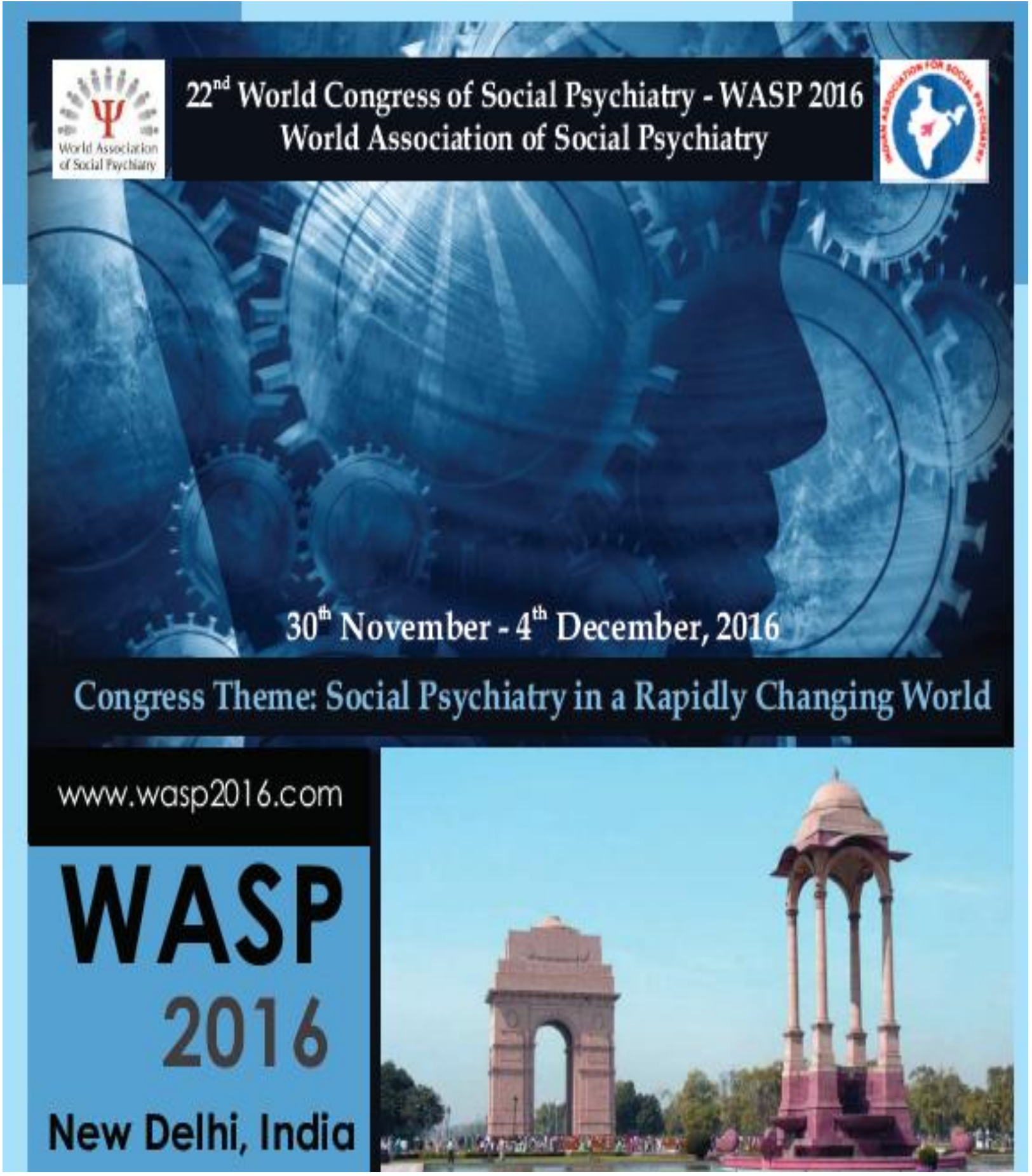

